\title{
Crime Sisters
}

\author{
E. Taverna
}

Ich käme ihr sehr gelegen, und ob ich etwas Zeit hätte, ihre Geschichte zu lesen? Heute Abend begänne die lange Buchnacht der «crime sisters» in der Oranienstrasse, die erste Lesung ihrer Kriminalgeschichte. Die Mordmethode bedürfe noch einer medizinkundigen Überprüfung, ob es noch möglich sei, dass ich ...? Ein echter Notfall.

Die Bewegung der «crime sisters» wurde in den USA von Sara Paretsky gegründet, um der männlichen Dominanz etwas entgegenzuwirken. Sie war dabei ebenso erfolgreich wie ihre Privatdetektivin Vic Warshawski, denn die Mordfrauen haben sich inzwischen weltweit in über fünfzig Ablegern organisiert. Susanne Rüster, Juristin und Hausfrau, Gastautorin von Kurzgeschichten in der Schweizerischen Ärztezeitung, gehört zur Berliner Gruppe, die sich regelmässig $\mathrm{zu}$ Workshops und Lesungen trifft. Gefragt sind dort weniger Stilkunde und schöne Deutschsätze, diskutiert werden die Regeln der Dramaturgie temporeicher Szenenwechsel, der plausiblen Abläufe, der spannenden Effekte und logischen Gedankengänge.

Ihre Geschichte «Partnerinnen» handelt von zwei in Hassliebe vereinten Juristinnen, von der rhetorischen Königin des Schwurgerichtssaals mit der perfekten Stimme und Gestik und der sprachgehemmten, aber hochbegabten Kollegin. «Anna war Reginas Kopf und Regina Annas Mund. Gemeinsam waren sie perfekt.» Es kommt, wie es kommen muss, Neid, Hass, Rachsucht und Rivalität um eine neue Mitarbeiterin lassen den Gefühlshaushalt explodieren.

Das Problem: soll ein Tennisball, aus nächster Nähe, mit maximaler Kraft geschlagen, den Kehlkopf oder besser die Halsschlagader treffen?

Im «Max und Moritz», dem Lokal an der berühmt-berüchtigten Oranienstrasse in Kreuzberg, treffen sich die Schwestern zur Probe. Im Saal vom ersten Stock üben die Damen und ein Herr mit Musiker an der Hammondorgel und Moderatorin im knappen Lederrock. Sie probt das Mikrofon, verspricht, die Nacht mit sündigen Desserts zu versüssen. Unten, wo das Publikum zur deftigen Hausküche ein Bier trinkt, werben Plakate für die kommende Kriminacht. Anders als die Speisekarte bieten sie «tödliche Happen zum Abend» oder «mörderische Bissen zur Nacht.» Die Autorinnen üben im Halbkreis das Finale, ein verbaler Digestive zum Abschluss, eine letzte Pointe, ein besonders gelungener Satz. Der Mann mit der Baseballkappe intoniert Mackie Messer, markiert die Übergänge mit Gruselakkorden und endet bei Pink Panther.

Aus nächster Nähe den Kehlkopf zu treffen, dürfte nicht gelingen, da sind wir uns rasch einig. Das Tennisduell entwickelt sich zum mörderischen Zweikampf, Anna lacht hysterisch, Regina wird wütend: «Rasende Trippelschritte, den Arm zum Schlag ausgeholt. Longline, Volley, Topspin. Eine rotgoldblonde Ballmaschine!» Können forensisch-klinische Überlegungen weiterhelfen? Kann ein Karotissinusreflex zum Tode führen? Bei älteren Patienten verlangsamt der einseitige Fingerdruck die Tachykardie; ein Handkantenschlag an die Halsseite wird Ohnmacht, Querschnittslähmung oder Tod verursachen; Boxer sprechen vom K.-o.-Punkt. Ich tippe auf den Vagusreflex, kombiniere ihn mit einer Karotisthrombose und lasse daraus ein Kammerflimmern entstehen. Das spricht für die Halsseite.

Krimis sind schon lange salonfähig, nicht erst seit Dürrenmatt, gegen Vorschuss vom Beobachter, den Kommissar Barlach erfand. Die feministische Urmutter der neuen Thrillerfrauen war die 1926 geborene Literaturprofessorin Amanda Cross. Inzwischen haben die Damen in allen Ländern aufgeholt. Selbst Krimimuffeln sind Donna Leon, Ingrid Noll, Batya Gur oder Christine Grän ein vager Begriff. Die meisten der anwesenden Autorinnen schreiben im Nebenberuf, einige wenige profimässig für Magazine und TV-Zeitschriften. Viele versorgen ein Szenepublikum mit Stoff; der anwesende Herr zum Beispiel die Schwulenleser und Lesben. Es gibt Spezialitäten wie den historischen Krimi oder den für die moderne Grossstadt, die etwas auf sich hält, also auch für Berlin oder Bern oder Zürich.

Für die sechste Buchnacht im «Max und Moritz» haben die «crime sisters» ein Motto von Gustave Flaubert gewählt: «Lies, um zu leben.»

Doch damit ist es vorbei. Dank medizinischer Hilfe kommt für Anna jede Hilfe zu spät, denn: "Anna wusste noch, dass sie ganz ans Netz musste. Sie fühlte den Puls im Hals, rasend schnell, fühlte sich wie ein Tier, das dem Jäger ins Feuer läuft. Regina streckte sich und holte aus. Ein Kanonenschlag traf Annas Halsschlagader. Sie taumelte, griff ins Leere.» 